\title{
PROMOVENDO O CONSUMO SUSTENTÁVEL: UM ESTUDO DE CASO
}

\section{PROMOTING A SUSTAINABLE CONSUMPTION: A CASE STUDY}

\author{
Mariana Vargas Braga da Silva \\ Pontifícia Universidade Católica do Rio Grande do Sul - PUCRS \\ Especialista em Gestão Estratégica de Pessoas \\ Porto Alegre, RS, Brasil \\ E-mail: mariana.braga@acad.pucrs.brpucrs.br \\ Ana Clarissa Matte Zanardo dos Santos \\ Pontifícia Universidade Católica do Rio Grande do Sul - PUCRS \\ Bolsista PNPD - Capes \\ Porto Alegre, RS, Brasil \\ E-mail: ana.clarissa@pucrs.br \\ Maira Petrini \\ Pontifícia Universidade Católica do Rio Grande do Sul - PUCRS \\ Professora/Pesquisadora do PPG em Administração \\ Porto Alegre, RS, Brasil \\ E-mail: maira.petrini@pucrs.br \\ Lisilene Silveira \\ Pontifícia Universidade Católica do Rio Grande do Sul - PUCRS \\ Doutoranda do PPG em Administração \\ Porto Alegre, RS, Brasil \\ E-mail: lisilene.silveira@hotmail.com
}

\section{RESUMO}

Este artigo objetiva compreender como as organizações desenvolvem ações que estimulem o consumo sustentável junto à comunidade, identificando os principais desafios enfrentados. Para tanto, adotou-se como estratégia de pesquisa o estudo de caso da empresa Insecta Shoes, a partir de uma abordagem qualitativa. Os dados primários foram coletados por meio de entrevistas e de um questionário. Os dados secundários foram coletados em páginas da empresa disponibilizadas na web. Foi realizada a análise de conteúdo e utilizou-se o software NVivo 10 para organizar os dados nas categorias: desenvolvimento das ações, relevância e reconhecimento das ações, e desafios enfrentados. Os resultados demonstram a preocupação com ações relacionadas à produção e à entrega de seus produtos, além da divulgação referente à conscientização da comunidade por meio de canais digitais, de eventos e workshops. As ações têm promovido o desenvolvimento local empregando artesãs locais. Percebe-se que os colaboradores e sócias estão engajados na causa e buscam realizar a mudança, apresentando-as à comunidade.

Palavras-chave: Consumo sustentável. Responsabilidade social. Sustentabilidade. Responsabilidade ambiental. Ações sustentáveis.

Data de submissão: 8 de julho de 2016.

\section{ABSTRACT}

This article aims to understand how organizations develop actions that encourage sustainable consumption in the community, identifying the main challenges. Therefore, we adopted the case study of Insecta Shoes company as a research strategy, from a qualitative approach. Primary data was collected through in-depth interviews with four employees and three partners, as well as an open questionnaire available on the web to six consumers. Secondary data were collected in company pages available on the web. We used content analysis and NVivo 10 to analyse and organize data in these categories: a) Development of actions, b) Relevance and recognition of actions and c) Challenges. The results demonstrate concern for actions related to the production and delivery of its products, as well as disclosure concerning the community awareness through digital channels, events and workshops. The actions have promoted local development employing local artisans. Employees and partners are engaged in the cause and seek to make the change and present it to the community.

Keywords: Sustainable Consumption. Social Responsability. Sustainability. Environmental Responsibility. Sustainable Initiatives.

Data de aprovação: 2 de agosto de 2017.

Agradecimento:

A segunda autora agradece à CAPES pelo apoio recebido. 


\section{INTRODUÇÃO}

O modelo de consumo adquiriu condição diferenciada ao longo dos últimos anos, advindo da natureza do sistema capitalista e das mudanças na sociedade de consumo Ocidental. As modificações nos estilos de consumo são percebidas na valorização dada pela sociedade ao poder de compra. Fortalece-se a crítica a sociedade capitalista e a cultura do consumo, questionando o ciclo de trabalho excessivo e o hiperconsumo e o endividamento (SCHOR, 1999; ROSENTHAL, 2006). Ainda assim, o consumo tornou-se uma atividade corriqueira na realidade da sociedade, cuja dimensão assume contornos preocupantes, em termos de prejuízos ambientais e climáticos, onde a abundância dos bens de consumo, continuamente produzida pelo meio industrial, é considerada um símbolo do sucesso da economia capitalista moderna (ARAÚJO, 2013).

Em razão dos múltiplos fatores prejudiciais do consumo extremo, a crise ambiental permanece com desafios para as sociedades modernas, exigindo alterações neste rumo civilizatório. Na tentativa de minimizar estes efeitos e em resposta ao estilo típico das sociedades materialistas, os sistemas sociais vêm se adaptando a uma nova realidade (GADOTTI, 2000) e propondo diferentes caminhos para a minimização desses impactos. Tipos de consumo mais sustentável buscam criar nos consumidores uma consciência ecologicamente seletiva, desenvolvendo novos hábitos de consumo responsáveis. Termos como consumo verde, consumo responsável e consumo consciente podem ser vistos como exemplos deste tipo de consumo mais sustentável, envolvendo a escolha de produtos ou serviços que levam em conta o contexto de produção, distribuição e impacto dos mesmos na sociedade e no meio ambiente. Tal escolha se dá a partir da consciência das consequências do consumo julgadas como negativas (OZCAGLAR-TOULOUSE, 2007; SZMIGIN et al., 2009; WILLIS; SCHOR, 2012).

Desta forma, uma solução alternativa aos padrões atuais da sociedade, requer um processo de mudança na responsabilidade, não apenas dos produtores, mas também dos consumidores, pelos seus impactos do consumo provocados na sociedade, na economia e no ambiente. Isto implica em uma sociedade ética, que esteja atenta ao coletivo e aos benefícios globais de suas ações (SILVA; MENK, 2012), por meio da multiplicação de movimentos que contemplem o equilíbrio entre o crescimento econômico, a proteção ambiental e a justiça social (SILVA et al., 2013). Em outras palavras, de um lado, busca-se por organizações que foquem no comprometimento com o meio ambiente, economia e sociedade e, por outro lado, considera o consumidor como personagem central desta necessária mudança nos padrões de consumo da sociedade moderna.

É neste contexto de busca pelo consumo consciente, visando uma sociedade mais justa e sustentável através da aproximação entre o consumidor e o produtor, que emerge a questão de pesquisa deste trabalho: como uma organização socialmente responsável desenvolve ações para o consumo sustentável junto a sua comunidade? Este artigo foi desenvolvido com o objetivo de investigar o desenvolvimento de ações de consumo consciente, sua relevância e os desafios enfrentados pela organização.

A pesquisa adotou uma abordagem qualitativa pela necessidade de aprofundar o conhecimento no campo de pesquisa. A estratégia de pesquisa foi um estudo de caso único e em profundidade da empresa Insecta Shoes, fundada em janeiro de 2014, em Porto Alegre, com o intuito de alterar os padrões de produção e criar um mundo com mais consciência. Apesar de ser uma empresa jovem, em 2015 teve um faturamento de $\mathrm{R} \$ 1$ milhão de reais, o que pode ser uma evidência da receptividade e do resultado de suas ações no 
mercado em que atua. Os dados primários foram coletados por meio de entrevistas em profundidade com quatro colaboradores e três sócias, além de um questionário aberto disponibilizado na web com seis consumidores. Os dados secundários foram coletados nas páginas da empresa (Site Corporativo, Blog e Facebook)

Como principais contribuições deste artigo podem ser citadas: a) necessidade de promover e desenvolver uma cultura baseada nas premissas da sustentabilidade, identificando metodologias e ferramentas que facilitem esse processo e b) a importância de criar instrumentos que demonstrem a transparência no processo produtivo, principalmente no que se refere aos custos, uma vez que produtos com características sustentáveis e artesanais podem ter um preço final elevado.

\section{A SUSTENTABILIDADE E O CONSUMO COLABORATIVO}

A sustentabilidade tem sido reconhecida como uma questão-chave para a sociedade do século XXI (KOMIYAMA; TAKEUCHI, 2006) e, segundo a abordagem Triple Botton Line apresentada por Elkington (2008), reúne três dimensões importantes: a equidade social, o desenvolvimento econômico e a preservação do meio ambiente. Munck e Souza (2009) constatam que a preocupação com as dimensões ambientais e sociais foi consequência das mudanças estruturais da sociedade e consequentes transformações institucionais. O foco das organizações, inicialmente, era o pilar econômico, ou seja, a autonomia do negócio, sem considerar as influências negativas que representavam, tais como a degradação ambiental, o abuso econômico, a exploração do trabalho, o poder destes na sociedade, a concorrência desleal. A dimensão ambiental foi, então, incluída na agenda das organizações, motivada, principalmente, por dúvidas crescentes em relação ao futuro do meio ambiente (BELLEN, 2006). Na década de 90, as pesquisas começaram a olhar a questão social como outro aspecto fundamental para a sustentabilidade (INSTITUTO ETHOS, 2015), tornando algumas práticas sustentáveis corriqueiras nas realidades corporativa. Yokomizo et al.(2009) afirmam que a preocupação em compreender os conceitos referentes à sustentabilidade e suas dimensões, bem como a intenção de incorporá-los no seu dia-a-dia passou a ser uma inquietação de muitas organizações.

Com isto, a adoção de processos de produção foi repensada para conservar a matéria-prima e a energia, reduzindo a produção de emissões de gases e resíduos tóxicos. Produtos também se tornaram fonte de modificação a fim de diminuir os impactos negativos, desde o momento de extração da matéria-prima até a definição do design. Ainda, serviços de entrega e empacotamento, também foram modificados (SEIFERT, 2014). Quanto à questão social o novo modelo da sustentabilidade buscou alterar a lógica dos negócios, possibilitando que cada organização assuma um novo papel na sociedade, na qual a inclusão e a transição para um padrão onde os princípios, a ética e a transparência podem anteceder a implementação de processos, produtos e serviços mais sustentáveis (INSTITUTO ETHOS, 2015).

Neste sentido, um dos pilares da sustentabilidade pode manifestar-se dentro das organizações por

meio de iniciativas de Responsabilidade Social Corporativa. Primeiramente, iniciativas associadas à "filantropia empresarial" conquistaram grande visibilidade no Brasil, uma vez que realizava ações privadas em benefício público. Entretanto, as ações estavam carregadas de referências históricas como caridade, paternalismo e assistencialismo, remetendo assim, uma conotação negativa (GODÓl-DE-SOUSA et al., 2009). Assim, as ações realizadas por esta organização deveriam buscar o benefício da coletividade 
(FREEMAN, 1984): o compromisso das empresas com o ambiente no qual estão inseridas transcende os aspectos econômicos e passa pela responsabilidade legal, ética e filantrópica. As organizações são instituições sociais que existem com autorização da sociedade, utilizam os recursos disponíveis e afetam a qualidade de vida da comunidade, sendo este o princípio norteador da responsabilidade social.

Ao buscar o crescimento sustentável, observando as dimensões social, ambiental e econômica, Munck et al. (2012) consideram importante salientar a responsabilidade dos gestores como orientadores e desenvolvedores de profissionais preocupados com as premissas de sustentabilidade. Os resultados de sua pesquisa apontam para a carência de modelos de gestão que permitam o desenvolvimento dos indivíduos para mobilizar, integrar e transferir conhecimentos, levando em consideração as exigências econômicas, sem comprometer, em curto e longo prazo, a sociedade e o ambiente. É importante salientar que a preocupação com o desenvolvimento sustentável pode produzir ganhos de imagem e visibilidade, além dos riscos de exposição trabalhista serem menores e menos propícios a problemas judiciais. Ou seja, é importante "adotar uma estratégia de gestão que atenda às demandas pela sustentabilidade, de modo que o resultado destas práticas seja favorável à otimização dos resultados organizacionais" (BIANCHI et al., 2013, p. 5).

No final da década de 90, o movimento intensificou-se com o surgimento de diversas instituições que se dedicaram às ações e à criação de indicadores, como a Fundação Abrinq, o Grupo de Institutos e Empresas - GIFE e o Instituto Ethos de Responsabilidade Social Corporativa. Estas instituições foram criadas com o objetivo de evidenciar a importância de ações sociais para os negócios e para a sociedade, em prol do meio ambiente e do desenvolvimento sustentável (TENÓRIO, 2015).

Ainda neste contexto, o Marketing Social tem como objetivo desenvolver campanhas que promovem mudança de comportamento dos consumidores, aumentando a participação no mercado e conquista de uma melhor imagem frente a sociedade. Tais ações objetivam melhorar condições sociais, ambientais e culturais, influenciando novas condutas e mudanças de comportamento. Campanhas de relações públicas bem administradas também podem surtir efeito, para elevar o nível do marketing socialmente responsável, a partir de uma postura adequada nos âmbitos legais, ético e da responsabilidade social (KOTLER; KELLER, 2006). Esta postura adequada nos âmbitos legais, ético e da responsabilidade social pode afetar decisões de compra, investimentos e até mesmo a escolha da organização que se deseja trabalhar. Em outras palavras, organizações socialmente responsáveis poderiam ser mais atrativas nas escolhas da sociedade.

Entretanto, visões não necessariamente convergentes podem ser encontradas. Para Araújo (2013) e Silva et al. (2013) muitos consumidores não relacionam suas atividades individuais ou coletivas de consumo aos prejuízos ambientais. A exploração de recursos, o consumo indiscriminado e a falta de consciência tornam eminente a necessidade da educação para uma ética ambiental. Já Bordin e Pasqualotto (2013) expõem que a conscientização ambiental, advinda dos incentivos organizacionais e de investimentos em educação, gerou um novo tipo de consumidor, que opta por escolhas conscientes de consumo. Ainda, afirmam que consumidores ecológicos ou verdes possuem atitudes ecologicamente conscientes, adquirindo produtos alinhados às causas ambientais e que originam pouco ou nenhum impacto ao meio ambiente. A pesquisa realizada por Coltro e Krugliankas (2006) com um grupo de estudantes apontou que $86 \%$ dos respondentes pagariam mais por produtos certificados, enquanto $74 \%$ afirmam que antes de comprarem, procuram pelos selos nas embalagens dos produtos. É importante destacar que a amostra do estudo foi composta por alunos 
do curso de Gestão Ambiental da tradicional Escola Superior de Agricultora, o que pode influenciar o alto grau de consciência socioambiental.

Corroborando, Haws et al. (2014) apontam que os valores de consumo verde estão diretamente relacionados aos recursos pessoais, não apenas aos coletivos. Portanto, devem ser desenvolvidos pelo indivíduo e compartilhados com a sociedade. Para os autores, os valores são resultado da relação positiva entre o uso inteligente dos recursos financeiros (expresso através da moderação, consciência de preço e autocontrole de compra) e o uso adequado dos recursos físicos (expresso pela moderação, uso de inovação e tendência a conservar o produto). Diante disso, o Instituto Akatu (2015a) considera que o maior desafio enfrentado para a conscientização de um mundo sustentável é a dificuldade de influenciar o comportamento das pessoas, seu jeito de viver e consumir, uma vez que as sociedades de consumo, por influência de sua natureza capitalista, apresentam uma forte cultura de adquirir produtos e serviços constantemente. $O$ consumo pode ser considerado a principal atividade do mundo moderno, sendo que este processo faz parte da vida social, função imprescindível da vida biológica, constituindo vínculos e relações humanas (PUJADAS et al., 2009).

As práticas de compras podem estar associadas, portanto, ao consumidor e seus interesses, além das experiências pessoais gratificantes, assim como remete níveis psicológicos e sociais na orientação de condutas de consumo a produtos e serviços determinados. Os benefícios internos e externos, suas respectivas prioridades, poderão ser analisados na prática do consumo, como o caso do consumidor de produtos orgânicos (CASTAÑEDA, 2012).

A preocupação com o meio ambiente já se refletia na Agenda 21 (1992), documento assinado no evento Rio-92, sobre a necessidade de alterar os padrões insustentáveis de consumo, afirmando que a sociedade carecia de ações eficazes. Governos, indústria, famílias e público em geral devem realizar esforços conjuntos, estimulando a reciclagem no nível de processo produtivo e produto, a redução do desperdício de embalagens e a introdução de produtos sustentáveis, apoiando os indivíduos na decisão de compra sustentável (AGENDA 21, 1992).

Contrapondo Haws et al. (2014), parece equivocado afirmar que os impactos das atividades de consumo são resultantes apenas do estilo de vida e percepções individuais do cidadão. O consumo é um ato coletivo da sociedade, um meio de se relacionar, instruído por valores culturais, experiências, vivências e identidades de consumo. Portanto, o modelo desenfreado de consumo da sociedade conduz à situação de deterioração ambiental, sendo contraditório ao crescimento urbano sustentável e exigindo a adoção de novas formas de produção e consumo consciente de toda a sociedade (CRUZ et al., 2007). Ainda sob esta perspectiva, conscientizar os consumidores de sua responsabilidade pelo descarte dos produtos e a destinação final de resíduos, estimulando-os a dotarem hábitos que privilegiem soluções ecologicamente responsáveis no processo de consumo pode ser um meio de harmonizar a relação entre consumo e meio ambiente (GONÇALVES; CESCON, 2013).

O Instituto Akatu (2015b) aponta caminhos para o consumo consciente, envolvendo empresa e cidadãos: a) produção local mais que global, b) o compartilhado mais do que o individual, c) o aproveitamento integral e não o desperdício, d) o saudável e não o prejudicial nos produtos e na forma de viver, e) o virtual mais que o material, f) a suficiência e não o excesso, g) a experiência e a emoção mais do que o tangível, h) a cooperação para a sustentabilidade mais do que a competição e i) a responsabilidade das empresas 
publicitárias para não incentivar o consumismo, ou seja, a propaganda deve instruir o consumidor com informações para escolha, favorecendo a sustentabilidade.

Em concordância com Johnstone e Tan (2015), os profissionais do marketing, o governo e os ativistas devem procurar por abordagens suaves em seus discursos sobre consciência de consumo e orientação aos consumidores. Os autores apontam a importância do consumidor se identificar com algum tipo de perda ao meio ambiente para se tornar mais engajado com a causa. Ademais, normas e legislações devem frequentemente ser repassadas para que os consumidores possam perceber como a degradação do meio ambiente afeta negativamente as futuras gerações e suas próprias vidas.

A sustentabilidade, quando presente como elemento cultural na sociedade, aumentará a exigência dos cidadãos e das organizações na produção, compra de bens e serviços, amplificando o espaço destinado a diferenciação dos produtos e comportamentos das empresas (INSTITUTO AKATU, 2015c). Portanto, a mudança aporta ações coletivas da sociedade, rumo a um destino ainda mais sustentável, em respeito ao meio ambiente e às gerações futuras.

\section{PROCEDIMENTOS METODOLÓGICOS}

A pesquisa desenvolvida teve uma abordagem qualitativa, pela necessidade de aprofundar o conhecimento no campo de pesquisa. Esta opção foi feita porque a abordagem qualitativa promove um meio para explorar as interpretações dos atores e estabelece um contexto onde a natureza dos dados permitir 0 aprofundamento analítico (BRYMAN, 1988).

A estratégia de pesquisa escolhida foi o estudo de caso, que permite analisar um fenômeno contemporâneo, no cenário estabelecido, proporcionando a compreensão de complexos fenômenos sociais (YIN, 2005). A opção pela realização de um estudo de caso único encontra reforço em Stake (2000) que afirma que tal escolha tem como objetivo produzir um conhecimento com certo grau de generalização a partir do estudo em profundidade de um caso concreto, que representa a questão de pesquisa sendo explorada. Em outras palavras, um caso único é uma alternativa válida que enfatiza a profundidade de compreensão de fenômenos sociais (DYER; WILKINS,1991; AHRENS; DENT, 1998). Ao estudar um caso único é esperado que este ofereça insights distintos, por isso o critério para seleção do caso deve buscar seu potencial revelador de uma situação crítica ao tema (CORLEY; GIOIA, 2004; LANGLEY; ABDALLAH, 2011).

Buscando atender as especificidades do estudo de caso, selecionou-se a empresa Insecta Shoes, fundada em janeiro de 2014, com o objetivo de alterar os padrões de produção e criar um mundo com mais consciência. A empresa foi idealizada pelas três sócias e, hoje, conta com quatro colaboradores. O core business da empresa é produzir e vender sapatos ecológicos, artesanais e veganos. Os calçados são feitos a partir da reutilização de roupas usadas, recicladas de garrafas de plástico descartadas e sem o uso de materiais de origem animal, reaproveitando e aumentando a vida útil de produtos e materiais. Além de oferecer um produto sustentável e exclusivo, a organização tem se preocupado com a questão social, adotando a estratégia de empregar mão-de-obra local, para estimular o trabalho artesanal e o desenvolvimento da comunidade. Ainda, tem trabalhado no sentido de conscientizar o público em geral quanto às questões ambientais a partir de notícias divulgas no site da empresa e da promoção de eventos e workshops aos interessados pelo tema. 
A empresa procura neutralizar os impactos de suas atividades utilizando o site sustentável como sua página principal de venda. Tratando da questão ambiental, ao final do ano, os acessos são contabilizados em $\mathrm{kg}$ de $\mathrm{CO}_{2}$ e para amenizar tais impactos, árvores são plantadas pela empresa. Preocupa-se, ainda, com o $\mathrm{CO}_{2}$ emitidos nas entregas das mercadorias, tendo em vista que a maioria de suas vendas ocorre pela internet. Desta forma, adota a entrega sustentável, com a utilização de bicicletas. Caso o cliente queira adquirir um produto de sua loja física, há um bicicletário com o objetivo de incentivar o uso de veículos não poluentes.

Quanto às embalagens, a entrega do produto é feita em sacolas de tecido, reduzindo o uso de plástico e papel. Em seu site, a empresa afirma que a sustentabilidade não se limita apenas ao produto e isso se reflete em diversas ações. Um exemplo é a preocupação com a escolha dos móveis e artigos de decoração do interior de sua loja física que são adquiridos em briques ou lojas de produtos semi novos.

Outros resultados quantitativos apontam que, em 2014, com apenas 1 ano de empresa, 500 peças de roupas e $150 \mathrm{~kg}$ de tecidos foram reaproveitados na produção de sapatos veganos. Além disso, $869 \mathrm{~kg}$ de $\mathrm{CO}_{2}$ foram neutralizados com as 55 árvores plantadas. Finalmente, considerando também o pilar econômico da sustentabilidade, destaca-se que a empresa faturou, em 2015 , seu segundo ano de funcionamento, $R \$ 1$ milhão de reais.

\section{Técnicas de Coleta e Análise de Dados}

A coleta de dados foi realizada a partir de diferentes fontes de evidências dentro do estudo de caso: a) fontes primárias (questionários e entrevistas individuais semi-estruturadas) e b) secundárias (pesquisa documental - site, blog e página no Facebook). As entrevistas e questionários foram as principais fontes de dados e os documentos serviram como fontes de triangulação e suplementares para o entendimento dos dados, bem como discrepância entre respondentes (MILES; HUBERMAN, 1994). Buscou-se, ainda, a triangulação dos respondentes contemplando três diferentes atores: sócias, colaboradores e consumidores.

No quadro 1 são apresentadas as quatro perguntas abertas que fizeram parte do roteiro de entrevista utilizado para coletar dados junto às sócias e colaboradores e as duas perguntas do questionário disponibilizado na web para os consumidores, conforme indicado na coluna Fonte. Além disso, foram analisados dados secundários nos meses de outubro e novembro de 2015. 
Quadro 1 - Protocolo de Pesquisa

\begin{tabular}{|c|c|c|}
\hline Categorias de Análise & Perguntas do Roteiro de Entrevista / Questionário & Fonte \\
\hline $\begin{array}{l}\text { Desenvolvimento de } \\
\text { Ações de Consumo } \\
\text { Consciente }\end{array}$ & $\begin{array}{l}\text { 1. Que ações a empresa adota para estimular o consumo } \\
\text { consciente (Produção, Distribuição)? } \\
\text { 2. Como a empresa comunica o trabalho realizado à } \\
\text { comunidade? } \\
\text { 3. Você utiliza as informações disponibilizadas pela } \\
\text { empresa na sua rotina? Como? }\end{array}$ & $\begin{array}{l}\text { Sócias / Colaboradores } \\
\text { (entrevista) } \\
\text { Sócias / Colaboradores } \\
\text { (entrevista) } \\
\text { Consumidores } \\
\text { (questionário via web) }\end{array}$ \\
\hline $\begin{array}{c}\text { Relevância e } \\
\text { Reconhecimento das } \\
\text { Ações }\end{array}$ & $\begin{array}{l}\text { 1. Você considera importante trabalhar em uma empresa } \\
\text { que se preocupe com o consumo consciente? Por quê? } \\
\text { 2. Por que você compra sapatos da empresa? }\end{array}$ & $\begin{array}{l}\text { Sócias / Colaboradores } \\
\text { (entrevista) } \\
\text { Consumidores } \\
\text { (questionário via web) }\end{array}$ \\
\hline Desafios Enfrentados & 1. Quais os desafios enfrentados neste processo? & $\begin{array}{l}\text { Sócias / Colaboradores } \\
\text { (entrevista) }\end{array}$ \\
\hline
\end{tabular}

Fonte: elaborada pelos autores

Foram entrevistados todos os colaboradores e sócias, no mês de dezembro de 2015. A empresa possui três sócias e quatro colaboradores, sendo três estagiárias e uma vendedora. Todas as entrevistas foram gravadas e transcritas. A coleta de dados junto aos consumidores foi realizada por meio de um questionário com duas perguntas abertas, gerado na ferramenta "Google Forms" e disponível para acesso no período de 13 de novembro a 07 de Dezembro de 2015. O link para o questionário foi enviado por e-mail para dez consumidores, dos quais seis responderam. Os consumidores foram acessados a partir do endereço eletrônico informado pela empresa e apresentaram o seguinte perfil: dois com experiência de consumo com a marca entre um a seis meses, três usuários com sete meses a um ano de utilização dos sapatos e apenas um com mais de um ano de experiência.

Os dados primários e secundários foram analisados por meio da técnica de Análise de Conteúdo (BARDIN, 2009). Na fase de pré-análise do material, os documentos e entrevistas foram lidos na íntegra, buscando-se conhecer o conteúdo. Em seguida, passou-se à exploração mais detalhada do material, codificando-os conforme as três categorias estabelecidas a priori a partir da literatura e da questão de pesquisa: a) Desenvolvimento de Ações, b) Relevância e Reconhecimento das Ações e c) Desafios enfrentados. Como o estudo buscava compreender como uma organização socialmente responsável desenvolve ações para o consumo sustentável junto a sua comunidade, as categorias foram estabelecidas no intuito de identificar as ações adotadas e como eram desenvolvidas, além de compreender a importância destas ações e se os colaboradores e clientes as percebiam. Da mesma forma, buscou-se identificar os desafios enfrentados no desenvolvimento das ações.

Com o objetivo de organizar os dados, foi utilizado o software NVIVO 10. Além de codificar as entrevistas conforme as categorias, foram estabelecidos os atributos dos respondentes, conforme o cargo que ocupam e o tempo de relacionamento com a Insecta Shoes. Esta codificação permitiu construir diferentes matrizes de codificação, cruzando as evidências a partir do perfil dos respondentes e das categorias analisadas. Assim, foi possível identificar as semelhanças e diferenças nas falas dos respondentes, conforme suas características. 


\section{APRESENTAÇÃO E DISCUSSÃO DOS RESULTADOS}

O objetivo dessa seção é apresentar os principais resultados, além de analisá-los à luz da literatura referenciada anteriormente. Os resultados serão demonstrados conforme as categorias apresentadas no Quadro 1, separadas em subseções.

\section{Desenvolvimento de Ações Sustentáveis}

Nesta categoria foram codificadas as falas dos entrevistados e informações obtidas por meio dos dados secundários relacionadas às ações realizadas pela empresa com objetivo de promover o consumo sustentável. Identificou-se dois grandes grupos de ações: (1) ações diretamente relacionadas ao processo de produção e entrega dos produtos, voltadas para a operação da empresa, e (2) ações direcionadas ao público em geral, voltadas para o desenvolvimento de uma consciência mais sustentável e dos benefícios que o consumo consciente pode gerar.

Ao acessar a página principal do site da empresa (INSECTA SHOES, 2015a), é possível encontrar informações concernentes à marca, estilo de produção, produtos e os diferenciais da empresa. Com interatividade, o site comunica o conforto, a modernidade e a jovialidade de sua marca. Em termos de produto, o site conta com uma variada e quase exclusiva produção de sapatos unissex, com muitas estampas e modelos da moda "Upcycling", que envolve o processo de transformar resíduos ou produtos inúteis e descartáveis em novos materiais ou produtos de maior valor, uso ou qualidade.

Em relação à produção, foram categorizadas 27 evidências nas entrevistas com os colaboradores e sócias. Dentre elas, as principais considerações são que a empresa está em constante busca por alternativas menos prejudiciais ao meio ambiente. Todos os colaboradores sentem-se parte deste processo, mesmo que sua principal função tenha outra finalidade, como relata a estagiária responsável pelo e-commerce. Tanto as sócias como os colaboradores destacaram o potencial do produto e as pesquisas por melhores materiais para reduzir o impacto de suas atividades. Seu processo produtivo não pode ser comparado com o de outras empresas calçadistas que utilizam couro como matéria-prima, uma vez que consomem mais água durante a produção e fazem uso de muitos recursos naturais e tóxicos. Um dos colaboradores afirmou que a empresa eliminou a água no processo e utiliza solventes de menor impacto. A realização de pesquisas por produtos à base de água, incorporando nos ateliers terceirizados significa uma pequena mudança também na produção de outros produtos terceirizados no local (MAY et al., 2003). As mercadorias da loja física são oferecidas em saquinhos de tecido, para melhor conservação e aproveitamento de material. Ademais, as entregas em Porto Alegre são realizadas com bicicletas. O processo de fabricação contempla a recirculação de materiais, corroborando com os princípios apresentados pelos autores que estudam a produção limpa (KOMIYAMA; TAKEUCHI, 2006; SEIFFERT, 2014; YOKOMIZO et al., 2009). Neste quesito, foi evidenciado um diferencial no encerramento do ciclo de vida do produto. Ainda que a produção seja mais limpa ao reduzir o consumo de poluentes e reutilizar materiais, falta criar alternativas para fechar o ciclo.

Uma das ações bastante destacadas pela empresa refere-se à preocupação com a mão-de-obra, principalmente, por ser artesanal. Todas as mercadorias são produzidas na região, para incentivar a contratação e promover o desenvolvimento local. O site afirma que a empresa se orgulha de empregar e assalariar devidamente seus artesãos, promovendo o desenvolvimento sustentável. Da mesma forma, nas 
entrevistas, os colaboradores e as sócias relataram a importância de desenvolver a comunidade na qual está inserida, trabalhando com mão-de-obra local, incentivar o crescimento econômico da região e assalariar de forma justa a todos os envolvidos. A remuneração justa tem um peso grande para os colaboradores que, em mais uma vez, apontam como a indústria da moda pode explorar seus colaboradores, o que não acontece nos ateliês da empresa. Este aspecto está em consonância com as orientações apontadas por Elkington (2008) e pelo Instituto Ethos (2015).

Para os clientes que desejam ir à loja física, existe um bicicletário no espaço dedicado ao estacionamento tradicional, incentivando o uso de bicicletas. Desta forma, a empresa procura pretende influenciar o comportamento e o estilo de viver de seus consumidores (BELLEN, 2006; INSTITUTO AKATU, 2015a; MAY et al., 2003). Outra iniciativa relacionada ao cuidado com a sociedade e meio ambiente referese à preocupação em plantar, em quantidade respectiva, árvores para neutralizar as emissões de $\mathrm{CO}_{2}$ gerada por seus servidores conforme a quantidade de acessos anuais no seu portal. O método é o selo de Site Sustentável, ou seja, cada acesso realizado, ao final do período, será transformado em áreas verdes. O resultado produzido até novembro de 2015 foram 55 árvores plantadas e redução de $870 \mathrm{~kg}$ de emissão de $\mathrm{CO}_{2}$.

Além da preocupação com ações relacionadas ao processo produtivo, um segundo grupo de ações voltadas para a conscientização do consumidor em relação às questões sócio-ambientais foi identificado. $O$ Blog (INSECTA SHOES, 2015b) divulgou o Workshop de Horta Caseira, que aponta alternativas para cultivar uma horta de orgânicos em casa e dicas alimentares. Adicionalmente, o blog continha um post destinado a exemplificar o "Upcycling", por exemplo, a transformação de uma calça em sapato (com o antes e depois do produto). A destinação consciente de resíduos sólidos, como tecido, foi matéria do blog, explicitando que cada metro de tecido pode ser convertido em dinheiro, no Banco de Tecidos. Estas publicações evidenciam os interesses organizacionais na promoção do desenvolvimento de programas sociais e a parceria com ações solidárias, em prol da comunidade (INSTITUTOS ETHOS, 2015a; FREEMAN,1984; TENÓRIO, 2015).

No período analisado, ainda houve a divulgação da marca consciente de sabonetes, com zero gordura animal e baixo impacto ambiental (ARAÚJO, 2013; DIAS, 2002; BRASIL, 1999), dicas e informações de reaproveitamento, comercialização e doação de peças de roupas que não são mais utilizadas, contribuindo para o desenvolvimento de uma cultura voltada à sustentabilidade (AGENDA 21, 1992; CRUZ et al., 2007; GONÇALVES; CESCON, 2013; INSTITUTO AKATU, 2015b). As sócias acreditam no potencial das informações publicadas nos veículos de comunicação utilizados pela empresa, incentivando os clientes refletirem sobre a responsabilidade por seus atos de consumo e comportamentos sustentáveis em seu cotidiano. Elas confirmam, ainda, que a missão da empresa é incentivar a pensar mais verde. Alguns autores reforçam a importância de as empresas assumirem este papel (BELLEN, 2006; INSTITUTO AKATU, 2015a; MAY et al., 2003).

O esforço da empresa é percebido nas respostas de três consumidores que afirmaram fazer uso das informações publicadas pela empresa na sua rotina. Um deles apontou que está mais atento ao consumo desenfreado, e sempre que está ao seu alcance, procura soluções que minimizem o seu impacto no meio ambiente. Este relato está de acordo com May et al. (2003) que aponta a importância das dicas, conhecimentos e informações para a minimização do impacto das atividades humanas e de consumo. Em oposição, um consumidor afirmou não utilizar o material disponibilizado pela empresa. 


\section{Relevância e Reconhecimento das Ações Sustentáveis}

A categoria Relevância e Reconhecimento das Ações Sustentáveis busca reunir as evidências relacionadas à percepção dos entrevistados quanto à importância das ações realizadas. Analisando inicialmente o site da empresa alguns usuários publicam comentários sobre a empresa e lançamentos de novos modelos e estampas dos sapatos da empresa. Importante destacar um comentário publicado no editorial mensal: "Atmosfera de sonho, a cara da marca...adoro a Insecta, está no topo da minha lista de indicações para clientes que querem peças com personalidade e eticamente produzidas. Parabéns!". Isto representa a valorização e o reconhecimento da marca entre o mercado, o destaque ao investimento em produção mais limpa, os cuidados com a sociedade e meio ambiente (ELKINGTON, 2008; INSTITUTO ETHOS, 2015).

A postagem sobre a nova parceria da empresa com a Move Institute - que atua com questões relacionadas à causa animal -, na página da empresa no Facebook (INSECTA SHOES, 2015c), relacionadas à preservação do mundo animal, obteve 790 curtidas com 28 comentários apreciando os modelos e expressando a satisfação dos consumidores ao receber o produto com valor simbólico. Esta postagem pode evidenciar que a empresa compreende e promove os interesses comunitários, através do desenvolvimento de programas e parcerias solidárias (INSTITUTOS ETHOS, 2015a; FREEMAN,1984; TENÓRIO, 2015). Da mesma forma, comentários postados no Facebook demostram a satisfação referente às ações da empresa que visam proporcionar melhores condições sociais, ambientais e culturais (KOTLER; KELLER, 2006). Estes comentários e avaliações remetem a consciência de consumo, o prestígio ao produto sustentável e como o consumidor está satisfeito da atitude de compra, que por vezes, consideram éticas de consumo. Ainda, compartilham as postagens com amigos para que outros possam conhecer a empresa e os produtos, difundindo os conhecimentos, as orientações, os valores e o viés sustentável repassados pela empresa (BRASIL, 1999; DIAS, 2002; ARAÚJO, 2013).

$\mathrm{Na}$ entrevista com a designer da empresa, foi possível perceber que o grande diferencial da marca é alinhar a beleza como um atrativo e despertar a importância da sustentabilidade nas pessoas. Ela afirma que alguns clientes da empresa reconhecem primeiro o conforto e a beleza dos produtos e, quando descobrem as ações e a preocupação com a sustentabilidade, ficam ainda mais satisfeitos e engajados com a causa, reforçando aspectos apontados por Komiyama e Takeuchi (2006), Yokomizo et al. (2009) e Seiffert (2014). Esse fato pode ser percebido no depoimento de um dos consumidores: ele afirma ser apaixonado pelos sapatos e pelos valores da marca. Da mesma forma, outros colaboradores apontam que é natural vivenciar todos os valores da empresa em suas rotinas, compartilhando-os com outras pessoas. A atendente de loja comenta que os valores e a filosofia da empresa são compartilhados por ela e estão sendo postos em prática nos seus momentos de vida, quando consome roupas, alimentos, energia.

É possível verificar que, em ambos os comentários, a consciência sustentável dos consumidores e colaboradores estão presentes, pois se identificam com os valores, comportamentos e compromissos da empresa, no estilo de produzir e consumir (BELLEN, 2006; INSTITUTO AKATU, 2015a; MAY et al., 2003). As sócias apontam que o consumo sustentável e a adoção de um estilo de vida que gere menor impacto ao ambiente estão "impregnados" na cultura organizacional. A equipe de trabalho é coesa e os colaboradores reforçam e complementam que a convivência e os exemplos positivos tornam mais natural a adoção de 
valores e atitudes de consumo consciente. O relato de uma colaboradora pode evidenciar tal fato: "Eu sempre gostei muito de comprar roupa e não refletia quanto a isso, e vários outros produtos. Não é só porque trabalho na Insecta, mas eu adquiri valores naturalmente e peso isso na minha escolha". As informações geram reflexões e efeito positivo para comprar menos e melhor, escolhendo por produtos ecológicos e responsáveis (AGENDA 21, 1992; CRUZ et al., 2007; GONÇALVES; CESCON, 2013; INSTITUTO AKATU, 2015b). É interessante observar que a própria colaboradora não percebe a alteração no seu comportamento, mas passa a adotar uma atitude mais sustentável a partir do ambiente em que está inserida.

Quando à relevância das ações junto à comunidade, três dos seis consumidores reconhecem as ações que a empresa tem desenvolvido, ressaltando as parcerias que vem sendo realizadas (INSTITUTO ETHOS, 2015; FREEMAN, 1984; TENÓRIO, 2015). Associam a marca com a causa social, uma vez que valorizam as artesãs locais, e ao Veganismo. Isso demonstra que a comunicação da empresa tem sido efetiva e reconhecem o intuito das ações (KOTLER; KELLER, 2006). Na íntegra, um consumidor comentou: "Sou cliente porque admiro a causa, a proposta da marca e acho os produtos lindos". Interessante ressaltar a posição de uma colaboradora que aponta a baixa atuação da empresa junto à comunidade. Esse fato pode ser explicado por dois motivos: o primeiro é a idade da empresa que, por ser muito jovem, ainda não consegue perceber resultados junto à comunidade. A outra justificativa pode ser uma explicação apontada pela própria colaboradora que avalia a atuação ambiental muito mais forte. Apesar da clara percepção, tanto por parte dos colaboradores como dos clientes, do alinhamento dos valores da Insecta Shoes com as questões sócioambientais, nas entrevistas foi possível perceber que ainda há espaços e lacunas na informação que é levada ao público sobre consumo consciente.

\section{Desafios enfrentados}

Esta categoria trata dos desafios enfrentados no desenvolvimento de ações que incentivem o consumo consciente. Tanto as sócias quanto os colaboradores apontaram a necessidade de maior transparência em relação aos custos de produção. As sócias afirmam que alguns de seus consumidores esbarram no preço do produto como barreira de consumo de produtos ecológicos. Tanto as sócias quanto os colaboradores procuram elucidar os diferenciais da marca para justificar os valores dos produtos. Um colaborador apontou que um Relatório Sustentável poderia ser uma solução viável para esclarecimento de dúvidas, de forma que o público pudesse compreender que assalariar devidamente os seus colaboradores e utilizar produtos de qualidade e de pouco impacto ambiental custa caro. Este dado é significativo, pois pode indicar o esclarecimento do colaborador quanto aos investimentos da empresa, além de refletir o engajamento em uma gestão ética e ainda mais transparente (INSTITUTO ETHOS, 2015). De acordo com as sócias e colaboradores, o último projeto colaborativo realizado com a Colibri - marca que trabalha com artesãs de comunidades locais, produzindo artesanato com materiais alternativos e reutilizados - resultou em questionamentos oriundos do valor do produto.

Apesar de três consumidores declararem em suas respostas seu engajamento com a causa defendida pela empresa, afirmando conhecer os valores da marca, adquirindo produtos alternativos e buscando reduzir o consumo, os outros três consumidores não demonstraram esta preocupação. Suas respostas apontaram que a escolha pelo produto da empresa foi motivada pelo estilo, conforto e beleza dos sapatos ofertados. Isto 
significa que nem todos os consumidores da empresa utilizam os produtos motivados pela compra sustentável (AGENDA 21, 1992; CRUZ et al., 2007; GONÇALVES; CESCON, 2013; INSTITUTO AKATU, 2015b). O interessante é que todos os consumidores foram indicados pela empresa e, por isso, supostamente estavam engajados à causa. Esse fato gera um questionamento: a empresa está conseguindo demonstrar a importância do consumo consciente com as ações que tem promovido?

Um dos colaboradores entende que o desafio é abrir a discussão para outros públicos. Nas palestras, workshops e eventos realizados, os debates são feitos com pessoas que possuem conhecimentos, com maior renda e condições de adotar medidas. Mas, seria interessante também mobilizar outros públicos e "sair da bolha". Nota que é evidente modificar ações coletivas na sociedade e conclui que a parcela de pessoas que não estão sendo atendidas necessita de informação e conhecimento para que possa ter consciência sobre os seus atos de consumo (AGENDA 21, 1992; CRUZ et al., 2007; GONÇALVES; CESCON, 2013; INSTITUTO AKATU, 2015b).

Dois desafios foram identificados: a) a necessidade de apresentar aos clientes, com transparência, o custo envolvido na produção do sapato a fim de justificar o seu preço e b) a necessidade de repensar a forma como a empresa comunica a importância da sustentabilidade e do consumo consciente, uma vez que nem todos os clientes tem a compra motivada por estes valores. É possível perceber que são poucos os desafios citados pelos entrevistados. Este fato pode ser explicado pelo fato da empresa ser jovem, estando, ainda, no início de sua trajetória. O olhar das sócias e dos colaboradores é mais voltado para as dificuldades relacionadas à inserção no mercado e à percepção dos clientes em relação ao produto (custo, qualidade e benefícios em utilizá-los). Novos desafios poderão ser identificados com o crescimento do negócio.

\section{CONSIDERAÇÕES FINAIS}

A pesquisa se propôs a compreender como uma organização socialmente responsável desenvolve ações para o consumo sustentável junto a sua comunidade. Partindo desta questão de pesquisa, foram realizadas entrevistas com as sócias e colaboradores da empresa e aplicado um questionário com consumidores. Além disso, foram analisados dados secundários obtidos a partir do site e blog da empresa, bem como a página no Facebook. Os dados foram analisados e codificados em três categorias: a) Desenvolvimento das ações sustentáveis, b) Relevância e Reconhecimento das Ações e c) Desafios enfrentados.

Em relação ao desenvolvimento das ações, é importante destacar a questão do desenvolvimento social, com o emprego de artesãs locais que fazem os sapatos manualmente, sendo remuneradas adequadamente. Outro aspecto é a busca por uma produção mais limpa, utilizando desde matéria-prima reutilizável até produtos que sejam menos tóxicos no processo produtivo. Ainda, preocupam-se com a entrega do produto utilizando bicicletas, utilizando a lógica da sustentabilidade em todo o processo. Em relação ao papel que a empresa assumiu na conscientização do mercado para o consumo consciente e sustentável, percebe-se que nem todos os clientes valorizam esta iniciativa e nem todas as motivações de compra do produto levam em consideração os valores sustentáveis da marca. Por um lado, é possível afirmar que a empresa procura desenvolver ações que promovam padrões sustentáveis de consumo e estejam voltadas à educação ambiental e desenvolvimento social da comunidade na qual está inserida, destacando-se a 
valorização da mão-de-obra local, a produção mais limpa e a divulgação de informações e promoção de eventos que busquem conscientizar a comunidade.

Por outro lado, ainda há lacunas para a divulgação das ações e o propósito pelo qual são realizadas com o intuito de promover o desenvolvimento da cultura do consumo consciente e cidadão. Evidências da existência destas lacunas é o fato de que as ações relacionadas à operação do negócio, por vezes, não são percebidas pelos consumidores, apesar de fazerem parte da missão e cultura da empresa. Quando analisadas a relevância e o reconhecimento das ações, os colaboradores sentem-se engajados e percebem que os valores fazem parte da cultura da empresa. Alguns consumidores valorizam os esforços da empresa no sentido de produzir de maneira sustentável e promover o consumo consciente. Entretanto, somente as sócias reconheceram, por exemplo, as ações relacionadas ao plantio de árvores para minimizar o impacto de suas atividades comerciais e as entrega de produtos com bicicletas em Porto Alegre elencadas como alternativa para diminuir a emissão de gases. Ou seja, mais uma evidência da existência de lacunas no desenvolvimento de ações para o consumo sustentável junto a sua comunidade.

Na busca por compreender como uma organização socialmente responsável desenvolve ações para o consumo sustentável junto a sua comunidade, acredita-se que essas lacunas merecem ser melhor exploradas. Apesar de efetivamente apresentar processos de produção limpa, preocupação com o ciclo de vida do produto e práticas de preservação e reaproveitamento de recursos, a organização trata de forma descasada suas ações relativas à operação de suas ações de comunicação com os clientes. Ora, se todas estas ações demonstram a preocupação efetiva da empresa com a sustentabilidade e o incentivo ao consumo consciente, por que não focar nelas em vez de somente divulgar ações indiretas à organização em si (como o workshop de horta caseira ou produtos de outras empresas também associadas ao consumo sustentável)? Esta é uma das lacunas que pode ser entendida como contribuição desta pesquisa. Ao se tratar das ações de fomento ao consumo sustentável realizadas por organizações socialmente responsáveis, tais organizações podem e devem aproveitar e explorar o alinhamento entre suas práticas e o consumo consciente. Quando as ações de comunicação para desenvolvimento do consumo consciente são descoladas das ações (ou práticas) sustentáveis relacionadas à operação, a organização deixa de explorar um grande potencial que reside em ter um discurso que está presente nas suas práticas operacionais.

Outra lacuna que pode ser destacada é a falta de expressão dada aos colaboradores. Por um lado, a análise do reconhecimento das ações sustentáveis evidencia um alto engajamento do público externo, não só pelo número de curtidas nas redes sociais, mas também pela existência de comentários e compartilhamentos. Por outro lado, fica claro que os colaboradores internos estão engajados e atribuem legitimidade à empresa ao perceber que os valores da mesma se refletem verdadeiramente nas ações operacionais, a exemplo dos processos de produção e entrega. Nesse sentido, o desenvolvimento de ações para o consumo sustentável junto à comunidade deve dar voz não somente ao público externo, mas também aos colaboradores internos das organizações, transmitindo legitimidade e transparência.

Como contribuição gerencial, o estudo aponta que a criação de um Relatório de Sustentabilidade que apresentasse o processo produtivo e os custos envolvidos, a fim de justificar o preço do produto final e promover uma relação mais transparente com os consumidores. 
A pesquisa teve como limitação a coleta de informação dos consumidores, tendo em vista que dos dez principais clientes, indicados pela empresa, apenas seis responderam ao roteiro disponível na web. Outro aspecto a ser ressaltado é a indicação de clientes pela empresa, fato que poderia ter gerado respostas bastante homogêneas, o que não aconteceu. Além disso, o fato de não conseguir realizar um contato presencial com os consumidores limita a profundidade dos dados coletados. Diante desta limitação relacionada principalmente com os consumidores, sugere-se em estudos futuros identificar os fatores que podem facilitar e dificultar a entrada de produtos sustentáveis no mercado. Adicionalmente, oportuno verificar os desafios do impulso de compra on-line ao consumo consciente.

Finalmente, este artigo procura deixar uma provocação e caminhos para novas pesquisas: o processo produtivo da empresa estudada busca reutilizar materiais e adotar recursos que pouco ou nada agridam a natureza. Entretanto, considerando a abordagem da sustentabilidade e do consumo consciente, é importante refletir sobre como planejar o fim da vida útil de seus produtos com alternativas para seu descarte ou reutilização. Os dados coletados mostram que, apesar desta preocupação existir, ela não é endereçada pela organização.

\section{REFERÊNCIAS}

AGENDA 21. Conferência das Nações Unidas sobre o Meio Ambiente e Desenvolvimento. Rio de Janeiro, 1992. Disponível em: http://www.onu.org.br/rio20/img/2012/01/agenda21.pdf . Acesso em 03/11/2015.

AHRENS, Thomas.; DENT, Jeremy. F. Accounting and organizations: Realizing the richness of field research. Journal of Management Accounting Research, v. 10, n.1, p.1-39, 1998.

ARAÚJO, Risolete Nunes de Oliveira. Consumidor, educação ambiental e consumo sustentável. Âmbito Jurídico, Rio Grande, XVI, n.116, 2013. Disponível em:

http://ambitojuridico.com.br/site/?n_link=revista_artigos_leitura\&artigo_id=13170\&revsta_caderno=10>. Acesso em 20/10/2015

BARDIN, Laurence. Análise de Conteúdo. Lisboa: Edições 70, 2009.

BELLEN, Hans Michael van. Indicadores de sustentabilidade: uma análise comparativa. Rio de Janeiro: FVG, 2006.

BIANCHI, Márcia; FAÉ, Mariana; GELATTI, Rosemary; ROCHA, João Marcos Leão. A responsabilidade social como parte integrante da cultura organizacional em empresas socialmente responsáveis: Análise de Conteúdo entre prática e o discurso. Revista Eletrônica Estratégias e Negócios, v.6, n.1, p. 160-191, 2013.

BORDIN, Danielle Pasqualotto; PASQUALOTTO, Nayara. A importância da Responsabilidade Social Empresarial para a sustentabilidade e o papel do Marketing Social. Capital Científico, vol.11, n.2, 2013

BRASIL. Lei n 9795, de 27 de abril de 1999. Dispõe sobre a educação ambiental, institui a Política Nacional de Educação Ambiental e dá outras providências. Brasília, 1999.

BRYMAN, Alan. Quantity and Quality in Social Research. London: Unwin Hyman, 1988.

CASTAÑEDA, Marcelo. Ambientalização e politização do consumo nas práticas de compra de orgânicos. Caderno CRH, Salvador, v. 25, n. 64, p. 147-160, 2012.

COLTRO, Alex; KRUGLIANSKAS, Isak. Estímulos de mercado às ações institucionais socioambientais: os Selos de Qualidade Assegurada são decodificados? Revista de Gestão USP, v. 13, n. 4, p. 61-77, 2006.

CORLEY, Kevin G.; GIOIA, Dennis A. Identity ambiguity and change in the wake of a corporate spin-off. Administrative Science Quarterly, v. 49, n. 2, p. 173-208, 2004.

CRUZ, Fernanda Talita da; ANDRADE, Júlia de; SILVA, Meyrieli. Das palafitas ao Conjunto Residencial Parque Barreiros: a relação da questão social e ambiental na intervenção do Serviço Social junto às famílias removidas de mangue seco. In: RODRIGUES, Sergio Claudio da Costa et al (Org.). Educação, ambiente e sociedade: novas ideias e práticas em debate. Vitória: ArcelorMittal, 2007.

DIAS, Genebaldo Freire. Pegada ecológica e sustentabilidade humana. São Paulo: Gaia, 2002.

DYER, W. Gibb; WILKINS, Alan. L. Better stories, not better constructs, to generate better theory: A rejoinder to Eisenhardt. Academy of Management Review, v.16, n.3, p. 613-619, 1991. 
ELKINGTON, John. Canibais com garfo e faca - seria sinal de progresso se um canibal utilizasse garfo e faca para comer? (Cannibals with forks). São Paulo: Makron Books, 2008.

FREEMAN, R. Edward. Strategic Management: a stakeholder approach. Toronto: Pitman, 1984.

GADOTTI, Moacir. Pedagogia da terra: Ecopedagogia e educação sustentável. São Paulo: Cortez, 2000.

GODÓI-DE-SOUSA, Edileusa; PEDREIRA, Luana Schoenmaker da; CAMPOS, Heloize Helena; MATTERN, Daniela. A Qualidade dos Relatórios de Sustentabilidade: uma Avaliação em Empresas do Ramo de Energia Elétrica. XXIII Encontro da ANPAD, São Paulo, 2009.

GONÇALVES, Marco Antonio; CESCON, Everaldo. Ética e consumo: o consumo como estratégia ético-política. Conjectura: Filos. Educ., v. 18, n. 3, p. 155-165, 2013.

HAWS, Kelly L.; WINTERICH, Karen Page; NAYLOR, Rebecca Walker. Seeing the world through GREEN-tinted glasses: Green consumption values and responses to environmentally friendly products. Journal of Consumer Psychology, v. 24, n. 3, p. 336-354, 2014.

INSECTA SHOES. Site da Empresa. Porto Alegre, 2015a. Disponível em: http://www.insectashoes.com/ Acesso em: 16/11/2015.

INSECTA SHOES. Blog da Empresa. Porto Alegre, 2015b. Disponível em: http://www.insectashoes.com/blog/. Acesso em: 16/11/2015.

INSECTA SHOES. Facebook da Empresa. Porto Alegre, 2015c. Disponível em:

https://www.facebook.com/insectainsecta. Acesso em: 10/11/ 2015.

INSTITUTO AKATU. Pesquisa Caminhos para estilos sustentáveis de vida em Brasília, 2015a. Disponível em: http://www.akatu.org.br/Temas/Sustentabilidade/Posts/Instituto-Akatu-apresenta-pesquisa-Caminhos-para-EstilosSustentaveis-de-Vida-em-Brasilia >. Acesso em: 20/10/ 2015.

INSTITUTO AKATU. Caminhos para produção de consumo consciente. 2015b. Disponível em: http://www.akatu.org.br/Temas/Consumo-Consciente/Posts/10-Caminhos-para-Producao-Consumo-Conscientes. Acesso em: 20/10/2015.

INSTITUTO AKATU. Integrando iniciativas públicas e privadas na produção e consumo consciente. 2015c. Disponível em: http://www.akatu.org.br/Temas/Consumo-Consciente/Posts/Integrando-iniciativas-publicas-e-privadas-producao-econsumo-sustentaveis. Acesso em: 20/10/2015.

INSTITUTO ETHOS. Responsabilidade social empresarial e sustentabilidade para a Gestão Empresarial. 2015. Disponivel em: http://www3.ethos.org.br/cedoc/responsabilidade-social-empresarial-e-sustentabilidade-para-a-gestaoempresarial/\#.VioTfhCrQ0Q >. Acesso em: 20/10/2015.

JOHNSTONE, Micael-Lee; TAN, Lay Peng. An exploration of environmentally-conscious consumers and the reasons why they do not buy green products. Marketing Intelligence \& Planinng, v. 33, n. 5, p. 804-825, 2015.

KOMIYAMA, Hiroshi; TAKEUCHI, Kazuhiko. Sustainability science: building a new discipline. Sustainability Science, v. 1 , n.1, p.1-6, 2006

KOTLER, Philip; KELLER, Kevin L. Administração de Marketing. São Paulo: Pearson Prentice Hall, 2006.

LANGLEY, Ann; ABDALLAH, Chahrazad. Templates and turns in qualitative studies of strategy and management. Research methodology in strategy and management, v. 6, p. 105-140, 2011.

MAY, Peter H.; LUSTOSA, Maria Cecília; VINHA, Valéria. Economia do meio ambiente: teoria e prática. Rio de Janeiro: Elsevier, 2003.

MILES, Matthew; HUBERMAN, A. Michael. Qualitative Data Analysis: an Expanded Sourcebook. Sage, 1994.

MUNCK, Luciano; SOUZA, Rafael Borim de. A relevância do ser humano no contexto de institucionalização e legitimação do paradigma da sustentabilidade. Revista de Gestão USP, v. 16, n. 3, p. 1-14, 2009.

MUNCK, Luciano; SOUZA, Rafael Borim de; ZAGUI, Cristiane. A Gestão por Competências e sua Relação com Ações Voltadas à Sustentabilidade. Revista de Gestão USP, v. 19, n. 3, p. 377-394, 2012.

OZCAGLAR-TOULOUSE, Nil. Living for" ethics": responsible consumption in everyday life. Research in Consumer Behavior, v. 11, p. 421, 2007.

PUJADAS, Carlos Héctor; FIGUEROA, María Fernanda; GARCÍA, María Laura; HERNANDÉZ, Juan Jesús. Consumo Sostenible ante la Crisis Global. Revista de Ciência Politica, n. 8, 2009.

ROSENTHAL, EDWARD. C. The era of choice: the ability to choose and its transformation of contemporary life. MIT Press, 2006.

SCHOR, Juliet. B. The Overspent American: Why. New York, 1999.

SEIFFERT, Maria Elizabete Bernardini. Gestão ambiental: instrumentos, esferas de ação e educação ambiental. São Paulo: Atlas, 2014. 
SILVA, Minelle Enéas da; MENK, Tomás Farcic. A prática do consumo e os níveis de consciência: um ensaio sobre consumo consciente sob a perspectiva filosófica de Hegel. VI Encontro Nacional de Estudos do Consumo e II Encontro Luso-Brasileiro de Estudos de Consumo. Rio de Janeiro, 2012.

SILVA, Minelle Enéas da; CZYKIEL, Renata; FIGUEIRÓ, Paola Schmitt; SANTOS, Wagner Soares Fenandes dos; GALVÃO, Ulysses Paiola. Um espelho, um reflexo! A educação para a sustentabilidade como subsídio para uma tomada de decisão consciente do administrador. Revista ADM. Mackenzie, v. 13, n.6, 2013.

STAKE, Robert. Case Studies In: DENZIN, Norman K.; LINCOLN, Yvonna S. Handbook of qualitative research. Sage Publications: California, 2000.

SZMIGIN, Isabelle; CARRIGAN, Marylyn; MCEACHERN, Morven. G. The conscious consumer: taking a flexible approach to ethical behaviour. International Journal of Consumer Studies, v. 33, n. 2, p. 224-231, 2009.

TENÓRIO, Fernando Guilherme. Responsabilidade social empresarial: teoria e prática. Editora FGV, 2015.

WILLIS, Margaret. M.; SCHOR, Juliet. B. Does changing a light bulb lead to changing the world? Political action and the conscious consumer. The Annals of the American Academy of Political and Social Science, v. 644, n. 1, p. 160-190, 2012.

YIN, Robert. K. Estudo de caso: planejamento e métodos. Porto Alegre: Bookman, 2005.

YOKOMIZO, Cesar Akira, GODÓI-DE-SOUZA, Edileusa, NAKATA, Lina Eiko; CORREAA, Hamilton Luiz. Negócios e sustentabilidade nas empresas brasileiras: adoção de práticas sustentáveis em 2006 e 2007. Biblioteca Digital de la Asociación Latino-Iberoamericana de Gestión Tecnológica, v.1, n.1, 2009. 